\title{
Review
}

\section{Induction of pluripotency by defined factors}

\author{
By Koji TAnABE, ${ }^{* 1}$ Kazutoshi TAKAHASHI ${ }^{* 1}$ and Shinya YAMANAKA*1,*2,† \\ (Contributed by Shinya YAMANAKA, M.J.A.)
}

\begin{abstract}
The "reversion of cell fate from differentiated states back into totipotent or pluripotent states" has been an interest of many scientists for a long time. With the help of knowledge accumulated by those scientists, we succeeded in converting somatic cells to a pluripotent cell lineage by the forced expression of defined factors. These established induced pluripotent stem (iPS) cells have similar features to embryonic stem (ES) cells, including pluripotency and immortality. The iPS cell technology provides unprecedented opportunities for regenerative medicine and drug discovery.
\end{abstract}

Keywords: iPS cell, reprogramming, pluripotent

\section{Initiation of "reprogramming science"}

The idea of inducing pluripotency in differentiated cells has its roots in cloning and nuclear transfer. In 1895, Hans Dreish succeeded in generating the first experimentally cloned animal, a sea urchin. ${ }^{1)}$ He found that when the embryo of a sea urchin was divided into single cells at the two- or four-cell stage, each of the separated single cells could develop into a complete sea urchin. His experiment revealed that all single cells from embryo had the ability to form the entire body. His results brought about the concepts of totipotency (the ability of cells to differentiate into all types of differentiated cells, including both extra and intra-embryonic cells), pluripotency (the ability of cells to differentiate into all types of intra-embryonic cells) and multipotency (the ability of cells to differentiate into several kinds of cells) to the life sciences.

These concepts were confirmed by Hans Spemann. In 1902, He divided the eggs of amphibians at the two cell stage into two parts along a cleavage plane using a baby's hair. He obtained two fully developed individual amphibians from each of the

*1 Center for iPS Cell Research and Application (CiRA), Kyoto University, Kyoto, Japan.

*2 Gladstone Institute of Cardiovascular Disease, San Francisco, California, U.S.A.

$\dagger$ Correspondence should be addressed: S. Yamanaka, Center for iPS Cell Research and Application (CiRA), Kyoto University, 53 Kawahara-cho, Shogoin Yoshida, Sakyo-ku, Kyoto 606-8507, Japan (e-mail: yamanaka@cira.kyoto-u.ac.jp). divided eggs. ${ }^{1)}$ At least, he has succeeded to generate clone amphibians using the nuclei at 16 cell stage. Beginning in the late nineteenth century, it was argued whether the nuclei of differentiated cells have the same information as the nuclei of fertilized eggs.

In 1893, August Weismann mentioned a principle of development in his Germ plasm theory. ${ }^{2} \mathrm{He}$ suggested that the germ cell (eggs and spermatozoa) include a "determinant", which was heritable information essential to decide on the functions and features of all somatic cells in the body. According to his theory, all determinants are inherited through germ plasm during cell division. However, the determinants are non-uniformity inherited among blastomeres during the division of the fertilized egg. Blastomeres lose some part of the determinants and decrease their abilities to differentiate and become committed to a specific cell lineage.

The use of nuclear transfer answered this question. The first nuclear transfers were published by Spemann in 1938.1),3) He firstly tightened the noose around a fertilized egg of a salamander to divide the eggs into two parts; a part with only cytoplasm and the other with both cytoplasm and nucleus. When the latter part divided and reached the sixteen-cell stage, he relaxed the noose to allow one of 16 nucli move into the part with only cytoplasm. Then he strongly tightened the noose to separate each part. Both separated parts grew up normal salamander embryos. These data demonstrated that the nuclei in the sixteen-cell stage have 
the same information as the nuclei of fertilized eggs. He proposed an idea of the nuclear transfer into enucleated eggs using the nuclei at the later stages of the development, but he could not realize the idea. ${ }^{1), 3)}$

The first successful nuclear transfer into enucleated eggs was realized by Briggs and King using tadpoles in 1952. ${ }^{4}$ The eggs developed into adult flogs. In their experiment, the efficiency of cloning frogs decreased when they used nuclei derived from embryos at later stages. They could not produce a cloned frog using the nuclei from a stage later than the tail bud. From these data, they concluded that when the cell fates were committed to specific fate during development, the nuclei of differentiated cells lost the information for the other types of cells during development.

However, about 10 years later, Sir John Gurdon succeeded in transplanting the nuclei of small intestinal epithelial cells of adult frogs into enucleated unfertilized eggs, and obtained tadpoles. ${ }^{5)}$ This result demonstrated that even nuclei of adult frogs maintain all the information necessary for tadpole development. In 1997, the famous cloned sheep, Dolly, was born after transplanting the nuclei of the mammary epithelium into an enucleated oocyte. ${ }^{6}$ So far, cloned animals have been generated from various species, such as mice, rabbits, cows, goats and pigs. Moreover, it was revealed that the nuclei of terminal differentiated cells, such as B cells and $\mathrm{T}$ cells, also retain the ability to return to the embryonic state. ${ }^{7)-9)}$ These data provided important knowledge that the information contained in the nuclei are not irreversibly deleted when cells commit to a specific fate during development. Somatic cells have the potential ability to be converted into other kinds of cells, even after differentiation and development. Moreover, these data suggested that oocytes include the factors that can revert the nuclear status of cells with differentiated cell fate to those with totipotency.

\section{Pluripotent stem cells}

In 1964, pluripotent embryonal carcinoma (EC) cells were isolated from teratocarcinomas. ${ }^{10)}$ The EC cells could differentiate into various types of cells in vitro. When EC cells were injected into blastocysts, they contributed to various tissues in chimeric mice. When the EC cells were fused with differentiated cells, the EC cells could reprogram these cells toward pluripotent states. ${ }^{11)}$ However, the contribution of EC cells in chimeric mice was low because of chromosomal abnormalities. EC cells were useless for genetic engineering because of their incompetence for germ line contribution. Moreover, the chimeric mice derived from EC cells frequently showed teratoma formation. ${ }^{12)}$

Many scientists subsequently tried to establish normal pluripotent stem cells for genetic engineering and biological applications. Embryonic stem (ES) cells were established from blastocysts in 1981. ${ }^{13), 14)}$ Embryonic germ (EG) cells were isolated from primordial germ cells (PGCs) in 1992.15),16) These cell lines kept normal karyotypes and also differentiated into all kinds of somatic cells after blastocyst injection. The EC cells, ES cells and EG cells could also reprogram the nuclei of somatic cells toward a pluripotent state when hybrid cells were produced after cell fusion. ${ }^{17), 18)}$ These data indicated that not only oocytes, but also pluripotent cells, had the ability to reprogram nuclei toward a pluripotent state, and also possessed "reprogramming factors".

To investigate whether reprogramming factors existed in cytoplasm or nucleus, neurosphere cells were fused with either the karyoplasts or cytoplasts of ES cells. The karyoplasts of ES cells could induce the expression of Oct3/4 and a partially reprogrammed state in these differentiated cells. ${ }^{19)}$ On the other hand, another group succeeded in establishing human ES cells in which the nuclei were completely replaced by the nuclei of somatic cells. ${ }^{20}$ They showed that a partially pluripotent state was obtained. These results could not define the intracellular location of reprogramming factors.

\section{Cell fate conversion by defined factors}

Cell fate conversions were also achieved using methods other than nuclear transfer and cell fusion. Interestingly, the forced expression of lineage-specific factors can directly convert a somatic cell's fate to that of a different cell without involving a pluripotent state. The first direct conversion of cell fate was achieved by the forced expression of the myogenic transcription factor (MyoD) into fibroblasts. The fibroblasts transduced with MyoD were converted to myoblasts in vitro. ${ }^{21)}$ Overexpression of $\mathrm{C} / \mathrm{EBP}$ induced the direct conversion from $\mathrm{B}$ cells to macrophages. ${ }^{22)}$ By suppressing Pax5, B cells can dedifferentiate into progenitor cells, which can differentiate into multiple hematopoietic lineages. ${ }^{23)} \mathrm{B}$ cells and $\mathrm{T}$ cells can be directly reprogrammed into macrophages by the overexpression of $\mathrm{C} / \mathrm{EBPa}^{24)}$ These data indicate that ectopic forced gene expression can induce the conversion of a cell fate. The over- 
expression of MyoD can induce the expression of skeletal muscle-specific genes in various somatic cells, such as retinal pigmented epithelia, neuroblastoma, melanoma and liver-derived cells. ${ }^{25), 26)}$ However, the expression of lineage-specific genes was not suppressed by MyoD overexpression in ectodermal and endodermal cells. Therefore, the forced expression of MyoD could completely reprogram only mesodermal cells, not ectodermal or endodermal cells. Taken together, these data provided important information showing that lineage-specific transcription factors can reprogram somatic cells into different types of cells. However, the forced expression of a single factor is not sufficient to convert the cell lineage beyond the germ layers.

\section{Medical application of pluripotent stem cells}

In 1998, human ES cells were established by James Thomson's group. Their establishment of human ES cells brought about the possibility that human ES cells could be used for medical applications. ES cells have two distinct features; immortality and pluripotency. Using these properties of ES cells, it is possible to obtain differentiated cells of many types in large quantities. Thus, human ES cell have been expected to be useful for regenerative medicine. However, ES cells have obstacles that hinder their clinical applications. One is immune rejection following transplantation into recipients. Human ES cells are derived from fertilized eggs from infertility clinics and thus have different immune antigens from patients who would receive transplantation of differentiated cells derived from ES cells. If the differentiated cells from ES cells are transplanted into recipients, the host's immune system will attack and kill these transplanted cells. In fact, differentiated cells from ES cells highly express the human leukocyte antigens (HLA) that would elicit immunological reactions.

In 2000, mouse nuclear transfer ES cells (ntES cell) were established to overcome these problems of immune rejection after transplantation. ${ }^{27)}$ To establish ntES cells, the nuclei from somatic cells of recipients were transplanted into enucleated unfertilized eggs. These transplanted eggs started to develop into embryos. The ntES cells were then established from inner cell mass of blastocysts of these embryos. Somatic cells derived from these ntES cells have the same immune antigens as the donors and would not be rejected after transplantation into the same individuals. These ntES cells have been established from not only mice, but also from monkey cells. ${ }^{27), 28)}$ However, human somatic-cell-nucleartransferred cells had arrested at 8 cell stage in development. ${ }^{29), 30)}$ On the other hand, when a nuclear of somatic cell was transplanted into intact oocyte, these triploid cells succeeded to develop to the blastocyst stage. The established cell lines had pluripotency to differentiate into three germ layers. These data indicated that human oocyte also had the ability to reprogram somatic cell nuclear into pluripotent fate. By improving the method of oocyte enucleation, finally, human ntES cells have also been established in 2013. ${ }^{31)}$ The nuclei of human fibroblasts were injected into 122 enucleated unfertilized eggs from nine donors. The development progressed to blastocyst stage in 21 embryos. Six human ntES cells were established. Four out of the six established ntES clones were derived from the same donor. The genetic background probably affects the efficiency of establishing ntES cells. There are also ethical issues regarding egg donation. The ethical issues regarding the usage of human embryos and eggs are another major drawback to the use of ES and ntES cells for clinical applications.

\section{Induction of pluripotency by defined factors}

To overcome these issues associated with human ES cells, we initiated a new concept to establish pluripotent stem cells. Based on the information generated from the nuclear transfer and direct conversion of cell lineage by defined factors, we hypothesized that the ES cell fate could also be induced in somatic cells. We speculated that the overexpression of important factors for ES cell lineage could convert differentiated cells into an ES cell fate, including the induction of pluripotency and immortality. In addition, we predicted that many of important factors required by ES cells would be specifically expressed in ES cells.

To identify genes specifically expressed in ES cells, we utilized publically available databases of expressed sequence tags (ESTs). Fortunately, Hayashizaki had released millions of EST datasets derived from various mouse organs, tissues and cells, including early embryos and ES cells. In addition, the National Center for Biological Information (NCBI) started providing a program, designated digital differential display (DDD), which allowed us to perform efficient analyses of these EST databases and to identify the ES cell-associated transcripts (ECATs). The Northern blot analyses confirmed that the ECATs were highly and specifically expressed in mouse ES cells and early embryos. 
We then analyzed the functions of the ECATs. We found that Nanog (ECAT4)-deficient ES cells differentiated into visceral or parietal endoderm, and could not maintain the properties of ES cells. Forced expression of Nanog maintained the self-renewal of ES cells, independent of leukemia inhibitory factor (LIF), a cytokine essential to maintain the pluripotency of mouse ES cells in culture. ${ }^{32), 33)}$ Pluripotency was not affected by the absence of ERas encoded by ECAT5. However, the teratomas derived from ERasnull ES cells were significantly smaller than those from wild type ES cells. These data suggested that Eras had important roles in the immortality of ES cells. ${ }^{34)}$ We thought that reprogramming factors would have important function to maintain the pluripotency in ES cells. We selected 24 candidate from the factors, including ECATs, which played important roles or were highly expressed in mouse ES cells.

In order to study whether some of these 24 candidates were capable of inducing the ES cell phenotype in somatic cells, we utilized mouse embryonic fibroblasts (MEFs), which carried the neomycin resistance gene in the Fbx15 locus $\left(\right.$ Fbx $\left.15^{\text {neo/neo }}\right)$. Since Fbx15 is encoded by ECAT3 and is only expressed in ES cells, but not in somatic cells like MEFs, the Fbx15 $5^{\text {neo/neo }}$ MEFs are sensitive to G418, whereas Fbx15 ${ }^{\text {neo/neo }}$ ES cells were resistant to the antibotics. ${ }^{35)}$ When each of the 24 candidates was introduced into Fbx $15^{\text {neo/neo }} \mathrm{MEFs}$ by means of retroviruses, no G418-resistant colonies emerged. However, when all 24 retroviruses were transduced at once, we obtained G418-resistant colonies, which were morphologically similar to mouse ES cells (Fig. 1A). Among the 24 factors, we found that four factors, including Oct3/4, Sox2, Klf4 and c-Myc (OSKM), were essential and sufficient for reprogramming cells. These reprogrammed cells had similar features to ES cells in terms of their expression profiles and epigenetic profiles. Moreover, these cells had pluripotency and differentiated into all three germ layers in teratomas (Fig. 1B). We designated the newly generated cells "induced pluripotent stem cells" (iPS cells). ${ }^{36)}$ The first generation iPS cells produced using the Fbx15 reporter system contributed to mouse embryos, but the chimeric embryos did not survive to birth. ${ }^{36)}$ These data indicated that fibroblasts were partially reprogrammed toward the pluripotent state, but were not completely reprogrammed.

To obtain fully reprogrammed iPS cells, we and others used other ES-specific genes essential for the
ES cell fate as reporters. Fbx15 is an ES-specific marker, but is not essential for ES cells. Even in the absence of fbx15 expression, ES cells can be established and remain pluripotent and self-renew. ${ }^{35)}$ On the other hand, Nanog and Oct3/4 are essential for ES cell fate. If the expression of Oct3/4 is suppressed by only half, the ES cells differentiate into trophectoderm. ${ }^{37)}$ When the Nanog or Oct3/4 locus was used as a reporter system, established iPS cells had the ability to contribute into chimeric mouse embryos which survived beyond birth (Fig. 2). Moreover, these improved iPS cells contributed to the germline of chimeric mice and produced F1 progeny. ${ }^{38)-40)}$ The iPS cells were also established using three factors without c-MYC, which harbors the highest risk of oncogenesis among these OSKM factors. ${ }^{41)}$

Some iPS cells even passed the most stringent test for pluripotency; tetraploid complementation. ${ }^{42)-46)}$ The cells of tetraploid embryos can contribute to extraembryonic tissues, but not to embryonic tissues. When the pluripotent stem cells were injected into tetraploid embryos, all embryonic tissues were derived from the injected cells. Tetraploid complementation can evaluate the pluripotency of stem cells more strictly than blastocyst injection. This is because when the pluripotent stem cells are injected into blastocysts, both the inner cell mass of the blastocyst and stem cells contribute to intraembryonic tissues. The injected stem cells are affected by the surrounding cells of the inner cell mass. In tetraploid embryos, host cells can not contribute to intraembryonic tissues. Only transplanted stem cells develop and differentiate into entire embryos in tetraploid embryos. When iPS cells are injected into tetraploid embryos, all of the tissues in the pups are completely and directly derived from the iPS cells. These data indicate that iPS cells are as competent as ES cells with regard to their differentiation potential.

Within less than a year after the first demonstration of OSKM mediated reprogramming in mouse cells, we reported the generation of human iPSCs using the same combination of reprogramming factors $^{47)}$ (Fig. 1C). James Thomson's group independently reported the generation of human iPS cells, with a different combination of reprogramming factors. They used OCT3/4, SOX2, NANOG and LIN28. ${ }^{48}$ Established human iPS cells generated using both combinations showed similar features to human ES cells, including their morphology, gene expression, epigenetic modifications and differentiation potential. These data indicated that human 
A

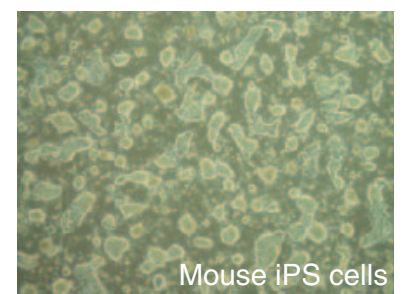

B
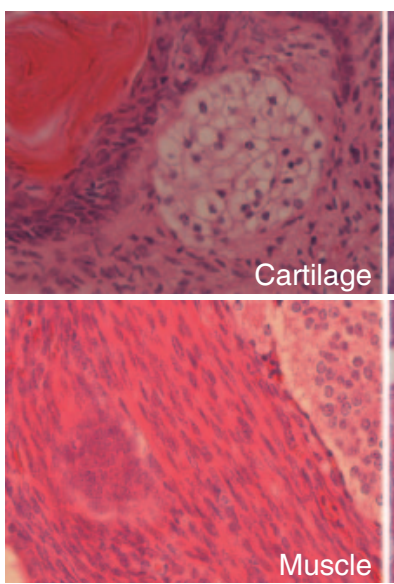
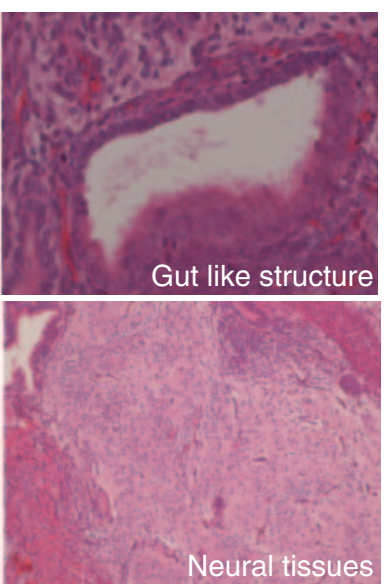

C

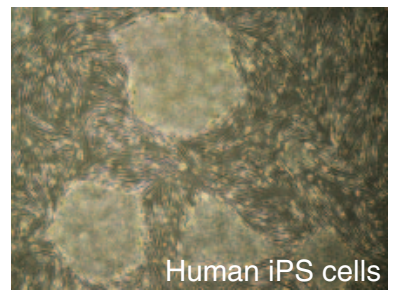

Fig. 1. A. Established mouse iPS cells with OSKM. These all iPS cells are established and cultured on STO cells expressing LIF and neomycin-resistant gene (SNL cells). B. Sections of teratomas derived from mouse iPS cells. C. Established human iPS cells established on SNL feeder cells.

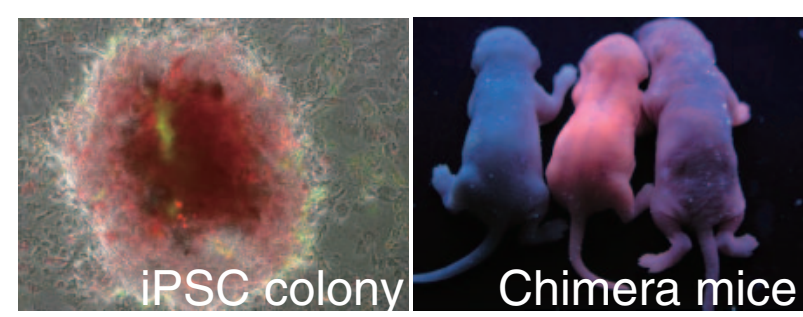

Fig. 2. The left figure shows the established mouse iPS cells from tail tip fibroblasts (TTFs) which constitutively express Ds-Red. These fibroblasts were introduced OSKM together with green fluorescent protein (GFP) using retrovirus system. Exogenous GFP are silenced during reprogramming. In the right figure, the mouse on the left is a control wild type mouse. Other two mice are chimera mice from Ds-Red iPS cells.

somatic cells could also be reprogrammed toward pluripotency using the forced expression of defined factors.

\section{Factors and pathway critical for iPS cell generation}

The efficiency of iPS cell induction is quite low; typically less than $1 \%$ of human fibroblasts that have received OSKM become iPS cells. However, we recently showed that the reprogramming process initiated in more than $20 \%$ of human fibroblasts after receiving OSKM. ${ }^{49)}$ TRA-1-60 $(+)$ is one of the most reliable surface markers specific for human pluripotent stem cells. Within seven days after OSKM transduction, more than $20 \%$ of transduced fibroblasts became positive for TRA-1-60. Gene expres- sion profiling confirmed that these TRA-1-60 (+) cells were partially reprogrammed cells. However, we found that the majority of TRA-1-60 $(+)$ cells reverted back into TRA-1-60 negative cells by day 15 post-transduction (Fig. 3A). These results showed that maturation, rather than initiation, is the major barrier during reprogramming toward iPS cells (Fig. 3B). In the initiation of reprogramming, OSKM induce the stochastic changes in gene expression. ${ }^{50)-52)}$ These intermediate reprogramming cells are heterogeneous population in gene expression both in human and mouse case. ${ }^{49,51), 52)}$ Some of intermediate cells path the limited step following after initiate stochastic step. Actually, lowering these barriers with such as knocking out of Mbd3 ${ }^{53)}$ overexpressing $\operatorname{Lin} 28^{49)}$ or $\operatorname{Lin} 41^{54)}$ promote the reprogramming efficiency. And then, in deterministic phase, they are committed into pluripotent cell fate with expressing predictive reprogramming markers such as Utf1, Esrrb, Dppa2 and Lin28 in mouse case. ${ }^{51), 52)}$ In this phase, the population of reprogramming cells gradually becomes homogenous. Several factors and pathways have been reported to play critical roles in iPS cell generation.

Histone modifications. Histone modifications regulate gene expression and stably maintain the cell lineages. Therefore histone modifications function as an obstacle to inducing changes in cell fates. In fact, the promoters of genes which show increased expression at the early stage of reprogramming have active histone marks, H3k4me3 (histone H3 lysine 4), in the fibroblasts even before the induction of 
reprogramming. In contrast, the promoters of genes that are activated at later stages of reprogramming carry both H3k4me3 and H3K27me3 (histone H3 lysine 27 ), or just H3K27me3. ${ }^{55)}$ At the very early stage of reprogramming (48 hours after transduction), OCT3/4, SOX2 and KLF4 bind to closed chromatin sites of promoters that are resistant to DNase digestion. H3K4s are not methylated in these regions. After the binding of OCT3/4, SOX2 and $\mathrm{KLF} 4$, these heterochromatic regions are opened. On the other hand, c-MYC can bind to opened chromatic regions of promoters that are modified with H3K4me1, 2 or 3 , but is unable to bind closed regions by itself. c-MYC can bind closed region only with the help of OCT3/4, SOX2 and KLF4. ${ }^{56)}$ Thus, OCT3/4, SOX2 and KLF4 function as initiators that open the epigenetic barriers and increase the accessibility of transcription factors involved in reprograming. However, OCT3/4, SOX2, KLF4 and cMYC cannot bind closed chromatic regions modified with H3K9me3 in the early phases of reprogramming. ${ }^{56)}$ The knockdown of SUV39H1/H2, a specific histone methyltransferase for H3K9me3, promoted the binding of OCT3/4 and SOX2, and increased the efficiency of iPS cell generation. ${ }^{56)}$ Moreover, in ES cells, c-Myc interacts with the NuA4HAT histone acetyltransferase complex and generates active histone markers, histone 3 and 4 acetylation. ${ }^{57), 58)}$ The NuA4HAT complex is important for ES cell identity. ${ }^{59)}$ It is probably thus critical for reprogramming that this complex is recruited to the correct loci by c-Myc. Mbd3 is a core component in the NuRD (nucleosome remodeling and deacetylation) repressor complex. Mbd3 directly interacted with OSKM reprogramming factors. ${ }^{53)} \mathrm{Mbd} 3 / \mathrm{NuRD}$ repressor complex is directly recruited to down-stream targets of OSKM which is important for cell fate changes into pluripotent cell fate. This interactions are important to inhibit the iPS cell induction by Mbd3. As a result, this complex inhibits the reactivation of OSKM targeted genes. Actually, depleting Mbd3 increased the efficiency of iPS cell induction. ${ }^{53)}$

The reprogramming efficiency is improved by lowering the barrier of histone modifications. Agents that have been reported to increase iPSC generation include BIX-01294, which is an inhibitor of G9a histone H3K9 methyltransferase, ${ }^{60)}$ and valproic acid (VPA), trichostatin A (TSA), suberoylanilide hydroxamic acid (SAHA) and sodium butyrate (NaB), which all are inhibitors of histone deacetylase. ${ }^{61), 62)}$ $\mathrm{NaB}$ promotes the reprogramming only in the presence of exogenously expressed c-Myc at the early stage of reprogramming. ${ }^{62), 63)}$ VPA can replace KLF4 and c-MYC to induce iPS cells from human neonatal fibroblasts. ${ }^{61)}$

DNA methylation. The promoters of several ES cell maker genes, such as Nanog and Oct3/4, are demethylated during reprogramming. ${ }^{36), 47)}$ During demethyltion process, 5-methylcytosine $(5 \mathrm{mC})$ is oxidized to 5-hydroxymethylation $(5 \mathrm{hmC})$ by teneleven translocation (TET) enzyme family. ${ }^{64), 65)}$ During iPS cell reprogramming, the $5 \mathrm{hmC}$ level are increased by TET1 activation. ${ }^{66)}$ Actually, TET1 and TET2 significantly increase mouse reprogramming efficiency by physical association with Nanog. ${ }^{67}$ ) TET1 dependent conversion from $5 \mathrm{mC}$ to $5 \mathrm{hmC}$ effect to reprogramming efficiency, but not pluripotency in human iPS cells. ${ }^{66)}$ It was found that the imprinted Dlk1-Dio3 gene cluster on chromosome $12 \mathrm{qF} 1$ was abnormally silenced in several iPS cells. These iPS cells poorly contributed to chimeric mice. Moreover, these iPS cells could not generate animals using tetraploid complementation. ${ }^{46}$ Thus proper DNA methylation changes are important to complete the reprogramming toward pluripotency. The reduction of the DNA methylation levels by a methyltransferase inhibitor, Aza-C, promoted the reprogramming efficiency. ${ }^{68)}$ Methylation changes affect not only the efficiency, but also the completion rate of reprogramming.

Reprogramming factors induce not only iPS cells, but also partially reprogrammed cells that express some ES markers and possess poor differentiation potentials. ${ }^{36), 68)}$ In these partially reprogrammed cells, the changes of DNA demethylation were insufficient on loci of ES cell-related genes, such as Nanog and Oct3/4. ${ }^{68)}$ DNA methyl transferase (Dnmt) 1 maintains the specific pattern of methylation during mitosis. The treatment with Aza-C or the suppression of the Dnmt1 level induces maturation from partially reprogrammed cells to completely reprogrammed iPS cells. ${ }^{68), 69)}$

Mesenchymal-to-epithelial transition. During the iPS cell induction from fibroblasts, cells undergo morphological changes that resemble the mesenchymal-to-epithelial Transition (MET). The reverse transition is the epithelial-to-mesenchymal transition (EMT), which plays important roles in development and cancer metastasis. The EMT occurs during gastrulation and delamination of the neural crest. ${ }^{70)}$ The gene expression changes associated with MET are detected at the early stage of mouse iPS cell induction, including the suppression of key mesen- 
chymal genes, such as Snail, Slug, Zeb1, Zeb2, Twist1, Twist2, N-cad and Fn and the upregulation of key epithelial genes, such as E-cadherin, Ocln, Cldn3, Dsp, Pkp1, Pkp3, Ep-CAM, Krt8 and Krt19. ${ }^{71)}$ These MET events occur before the induction of ES cell markers such as Nanog, Sall4 and Oct3/4, as well as the surface marker, SSEA-1. Moreover, the acceleration of MET promoted the reprogramming efficiency of mouse iPS cell induction. ${ }^{72)}$

It is known that TGF- $\beta$ can induce the EMT at least partially through the activation of Snail. ${ }^{73), 74)}$ TGF- $\beta 1$ treatment or overexpression of Snail decreases the reprogramming efficiency. ${ }^{71)}$ Conversely, TGF- $\beta$ receptor inhibitors and Alk5 inhibitors increase the reprogramming efficiency from fibroblasts. ${ }^{71)}$

Bone morphogenetic proteins (BMPs) are another important signal for the MET. BMP4 induces the expression of miRNA 205 and 200 families, which are key factors involved in the MET. ${ }^{72)}$ BMPs elicit important signals to maintain the pluripotency in mouse ES cells, together with leukemia inhibiting factor (LIF) signaling. ${ }^{75)}$ BMP2, BMP7 and BMP9 increase the reprogramming efficiency with OSKM. ${ }^{72)}$ Conversely, the reprogramming efficiency was decreased by suppressing the BMP signaling using a BMP receptor antagonist, dorsomorphin, or a soluble BMP ligand antagonist, Noggin. This reduction of reprogramming efficiency was rescued by the overexpression of miRNA 200 family members. ${ }^{72)}$ The expression of epithelial genes was induced by the overexpression of Klf4, which bound the promoter of E-cadherin. KLF4 can be replaced by BMP4 to induce iPS cells. ${ }^{76)}$ These data suggested that the MET signaling induced by BMP and miRNA 205/ 200 families were important during the early phase of reprogramming.

\section{Medical and pharmaceutical applications of iPS cells}

The iPS cell technology has opened new and unprecedented ways to investigate and potentially cure diseases. The iPS cells derived from patients can be used in at least two ways: regenerative medicine and drug discovery (Fig. 4).

Regenerative medicine. The first potential usage of iPS cells in clinics is regenerative medicine. Human iPS cells can differentiate into various functional somatic cells. Transplantation of these differentiated cells is expected to result in functional recovery in patients. In fact, the transplantation of differentiated cells derived from iPS cells has already been shown to mitigate the disease phenotypes in mouse models of sickle cell anemia, ${ }^{77)}$ platelet deficiency, ${ }^{78)}$ Parkinson's disease ${ }^{79)}$ and spinal cord injury. ${ }^{80), 81)}$ iPS cells can be generated from patients' own somatic cells. Differentiated cells from autologous iPS cells would not be rejected by the immune system after transplantation. ${ }^{82)-84)}$ However, making iPS cells from each patient would take at least several months and would not be cost-effective. Alternatively, iPS cell banking could be established in advance from healthy volunteers. ${ }^{85), 86)}$ Immune response could be decreased if the human leukocyte antigen (HLA) is matched between donors and recipients. It is thought that $90 \%$ of the Japanese population would be covered by 140 clones of iPS cells derived from HLA homogenous donors. To collect these 140 clones of HLA-homogenous iPS cells, the HLA type will need to be investigated in about $1.6 \times 10^{5}$ Japanese people. ${ }^{87)}$ Collaboration with existing banking efforts, such as platelet transplantation, bone marrow transplantation, and cord blood transplantation would be required to cover such large populations.

Methods used to generate the iPS cells are critical for regenerative medicine. Originally, retroviral or lentiviral systems were used to generate the first human iPS cells. The reprogramming factors were integrated into genomes when using these systems. There insertions in the genome could give rise to severe damage to the induced cells. However, iPS cells can now be established without the integration of transgenes. ${ }^{87)-92)}$ These iPS cells are more suitable for clinical applications. Additionally, manipulations of the culture conditions used for the iPS cells, including the use of Xeno-Free culture systems, also should be evaluated in more depth for transplantation. Recently, the three-dimensional structures of the retina and pituitary gland were generated by self-organization of pluripotent stem cells in vitro. ${ }^{93)-95)}$ Moreover, functional rat pancreases were generated in Mouse body. Pdx1 deficient mice die after birth because of pancreatic insufficiency. Rat pluripotent stem cells were injected into Pdx1 - / - mouse blastocyst to rescue them. The rescued mouse had functional pancreas derived from rat pluripotent stem cells. ${ }^{96)}$ On the other hand, vascularized and functional human livers were generated in vivo by transplantation of liver buds made in vitro. ${ }^{97)}$ The combination of $3 \mathrm{D}$ differentiation and improved systems for iPS cell induction will provide new strategies for regenerative medicine. 
A

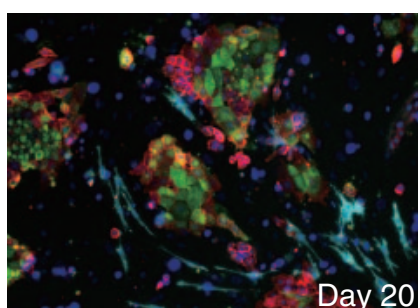

Red: TRA-1-85

Green: TRA-1-60

Aqua: CD13

Blue: DAPI
B

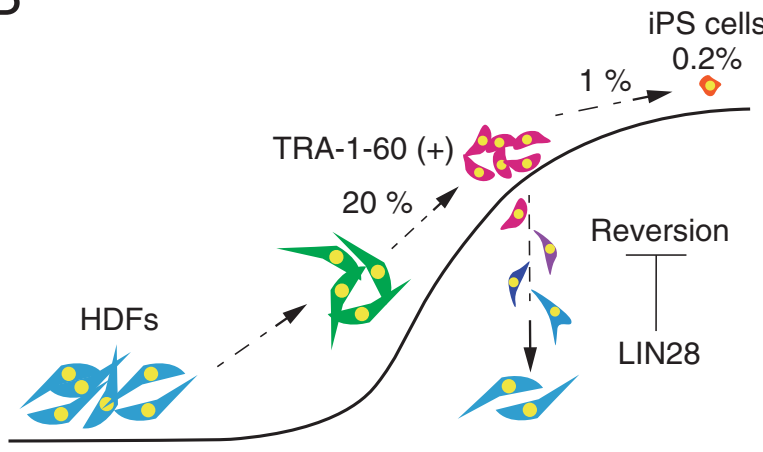

Fig. 3. A. Reprogramming cells (TRA-1-60 positive) and reverted cells (TRA-1-80 positive/TRA-1-60 negative) during iPS cell induction on day 20 post-transduction. On 11 days post-transduction, sorted TRA-1-60 positive cells were seeded on SNL feeder cells. These cells were immune site stained with each anti body 9 days after seeding. TRA-1-80 was human specific antigen. All red cells were derived from seeded TRA-1-60 positive cells on 11 days post-transduction. TRA-1-60 negative/TRA-1-85 positive cells were reverted cell from TRA-1-60 positive cells. Several reverted cell started to express CD13 (Aqua) and got fibroblastic identities again. B. A model of reprogramming process. The majority of transduced cells with OSKM started to change toward pluripotent state in the gene expression profile and initiated reprogramming process. About $20 \%$ transduced cells became positive for TRA-1-60. Just TRA-1-60 positive cells could mature to iPS cells. During maturation steps, majority of TRA-1-60 positive cells went back to fibroblastic cell fate. LIN28 could inhibit this reversion.

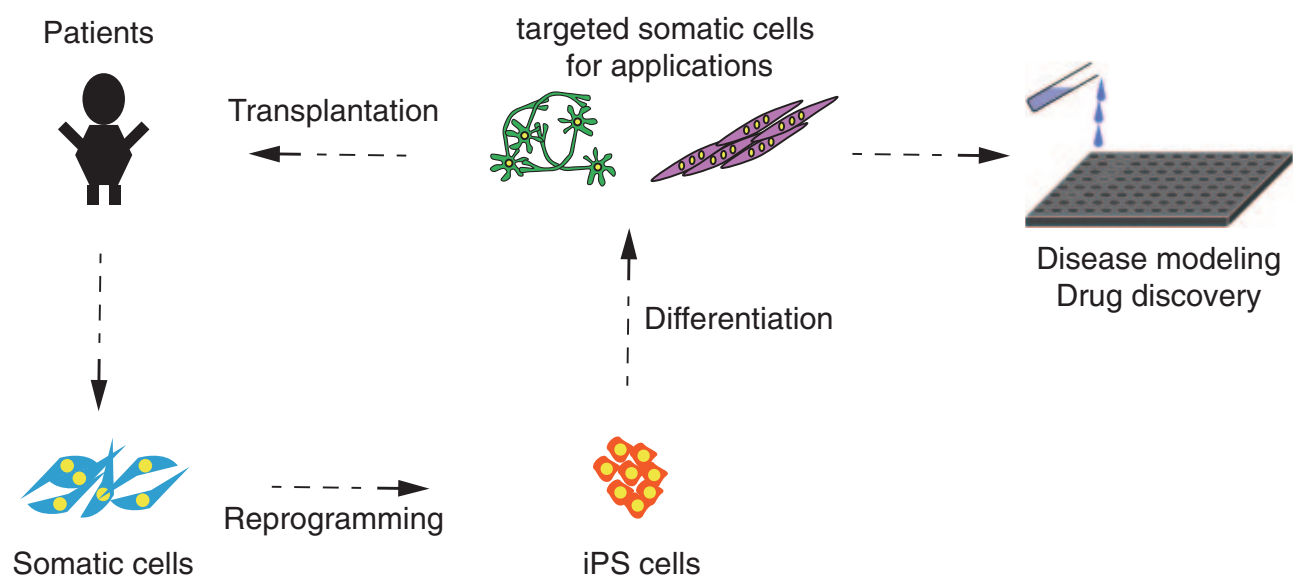

Fig. 4. A model of clinical applications with iPS cells. iPS cells derived from patients are useful for regenerative medicine and drug screening.

Drug discovery. Another important usage of iPS cells is making disease models and screening chemicals and natural derivatives to identify therapeutic drug candidates. The differentiated cells derived from patient-specific iPS cells are expected to reconstruct disease phenotypes in vitro. The first disease-specific iPS cells were generated from patients with amyotrophic lateral sclerosis (ALS). However, the recapitulation of disease phenotypes in vitro was not pursued in that study. ${ }^{98)}$ The first disease phenotype reconstructed in vitro using iPS cells was derived from cells obtained from spinal muscular atrophy (SMA) patients. In this disease model, it was revealed that these differentiated neural cells derived from patient-specific iPS cells were responsive for drug treatment. ${ }^{99), 100)}$ Subsequently, many reports have been published regarding disease modeling and drug screening using patient-derived iPS cells. For example, we have shown that anacardic acid can diminish the phenotype in a disease model of ALS using patient-specific iPS cells. ${ }^{101)}$

An important issue regarding patient-specific iPS cells is the inclusion of a proper control. The genetic and epigenetic backgrounds vary widely 
among people, and even the family members of the patients can have significantly different backgrounds. If the iPS cells derived from healthy donors are used as a control, the genomic or epigenetic background may affect the phenotypes. An ideal control is the patient's own iPS cells, in which the causal gene mutation(s) for the disease are repaired, such as by using zinc-finger nuclease, ${ }^{102)-104)}$ transcription activator-like effector nucleases (TALENs) ${ }^{105), 106)}$ or the Clustered Regularly Interspaced Short Palindromic Repeats (CRISPR)/Cas9 system. ${ }^{107)}$

\section{Conclusion}

Since the first demonstration of the generation of iPS cells in 2006, the iPS cell technology has shown remarkable progress thanks to numerous researchers all over the world. The very first clinical trial using the technology for patients suffering from age-related macular degeneration has been approved by the Japanese government. However, many issues still need to be overcome prior to the general use of the iPS cell technology in the clinical setting. The manipulation of cells and the culture conditions should be optimized to generate clinical-grade differentiated cells derived from iPS cells. In particular, the quality and safety of cells should be evaluated carefully from multiple points of view.

\section{Acknowledgements}

We would like to thank the members of the Yamanaka laboratories for their tireless support.

\section{References}

1) Gilbert, S.F. (2010) Developmental Biology. 9th ed. Sinauer Associates, Inc., Sunderland.

2) Weismann, A. (1893) The Germ-Plasm: A Theory of Heredity. Charles Scribner's Sons., New York.

3) Spemann, H. (1938) Embryonic Development and Induction. Hafner Publishing Co Ltd., New York.

4) Briggs, R. and King, T.J. (1952) Transplantation of living nuclei from blastula cells into enucleated frogs' eggs. Proc. Natl. Acad. Sci. U.S.A. 38 (5), 455-463.

5) Gurdon, J.B. (1962) The developmental capacity of nuclei taken from intestinal epithelium cells of feeding tadpoles. J. Embryol. Exp. Morphol. 10, 622-640.

6) Wilmut, I., Schnieke, A.E., McWhir, J., Kind, A.J. and Campbell, K.H. (1997) Viable offspring derived from fetal and adult mammalian cells. Nature 385 (6619), 810-813.

7) Hochedlinger, K. and Jaenisch, R. (2002) Monoclonal mice generated by nuclear transfer from mature B and T donor cells. Nature 415 (6875),
1035-1038.

8) Eggan, K., Baldwin, K., Tackett, M., Osborne, J., Gogos, J., Chess, A., Axel, R. and Jaenisch, R. (2004) Mice cloned from olfactory sensory neurons. Nature 428, 44-49.

9) Inoue, K., Wakao, H., Ogonuki, N., Miki, H., Seino, K., Nambu-Wakao, R., Noda, S., Miyoshi, H., Koseki, H., Taniguchi, M. and Ogura, A. (2005) Generation of cloned mice by direct nuclear transfer from natural killer $\mathrm{T}$ cells. Curr. Biol. 15 (12), 1114-1118.

10) Kleinsmith, L.J. and Pierce, G.B. Jr. (1964) Multipotentiality of single embryonal carcinoma cells. Cancer Res. 24, 1544-1551.

11) Miller, R.A. and Ruddle, F.H. (1976) Pluripotent teratocarcinoma-thymus somatic cell hybrids. Cell 9 (1), 45-55.

12) Papaioannou, V.E., Gardner, R.L., McBurney, M.W., Babinet, C. and Evans, M.J. (1978) Participation of cultured teratocarcinoma cells in mouse embryogenesis. J. Embryol. Exp. Morphol. 44, 93-104.

13) Evans, M.J. and Kaufman, M.H. (1981) Establishment in culture of pluripotential cells from mouse embryos. Nature 292 (5819), 154-156.

14) Martin, G.R. (1981) Isolation of a pluripotent cell line from early mouse embryos cultured in medium conditioned by teratocarcinoma stem cells. Proc. Natl. Acad. Sci. U.S.A. 78 (12), $7634-7638$

15) Matsui, Y., Zsebo, K. and Hogan, B.L. (1992) Derivation of pluripotential embryonic stem cells from murine primordial germ cells in culture. Cell 70 (5), 841-847.

16) Resnick, J.L., Bixler, L.S., Cheng, L. and Donovan, P.J. (1992) Long-term proliferation of mouse primordial germ cells in culture. Nature 359 (6395), 550-551.

17) Tada, M., Tada, T., Lefebvre, L., Barton, S.C. and Surani, M.A. (1997) Embryonic germ cells induce epigenetic reprogramming of somatic nucleus in hybrid cells. EMBO J. 16 (21), 6510-6520.

18) Cowan, C.A., Atienza, J., Melton, D.A. and Eggan, K. (2005) Nuclear reprogramming of somatic cells after fusion with human embryonic stem cells. Science 309 (5739), 1369-1373.

19) Do, J.T. and Scholer, H.R. (2004) Nuclei of embryonic stem cells reprogram somatic cells. Stem Cells 22 (6), 941-949.

20) Verlinsky, Y., Strelchenko, N., Shkumatov, A., Kukharenko, V., Verlinsky, O. and Kuliev, A. (2006) Cytoplasmic cell fusion: Stembrid technology for reprogramming pluripotentiality. Stem Cell Rev. 2 (4), 297-299.

21) Davis, R.L., Weintraub, H. and Lassar, A.B. (1987) Expression of a single transfected cDNA converts fibroblasts to myoblasts. Cell $\mathbf{5 1}$ (6), 987-1000.

22) Xie, H., Ye, M., Feng, R. and Graf, T. (2004) Stepwise reprogramming of $\mathrm{B}$ cells into macrophages. Cell 117 (5), 663-676.

23) Cobaleda, C., Jochum, W. and Busslinger, M. (2007) Conversion of mature B cells into T cells 
by dedifferentiation to uncommitted progenitors. Nature 449 (7161), 473-477.

24) Laiosa, C.V., Stadtfeld, M., Xie, H., de AndresAguayo, L. and Graf, T. (2006) Reprogramming of committed $\mathrm{T}$ cell progenitors to macrophages and dendritic cells by C/EBP alpha and PU.1 transcription factors. Immunity 25 (5), 731-744.

25) Weintraub, H., Tapscott, S.J., Davis, R.L., Thayer, M.J., Adam, M.A., Lassar, A.B. and Miller, A.D. (1989) Activation of muscle-specific genes in pigment, nerve, fat, liver, and fibroblast cell lines by forced expression of MyoD. Proc. Natl. Acad. Sci. U.S.A. 86 (14), 5434-5438.

26) Choi, J., Costa, M.L., Mermelstein, C.S., Chagas, C., Holtzer, S. and Holtzer, H. (1990) MyoD converts primary dermal fibroblasts, chondroblasts, smooth muscle, and retinal pigmented epithelial cells into striated mononucleated myoblasts and multinucleated myotubes. Proc. Natl. Acad. Sci. U.S.A. 87 (20), 7988-7992.

27) Rideout, W.M. 3rd, Wakayama, T., Wutz, A., Eggan, K., Jackson-Grusby, L., Dausman, J., Yanagimachi, R. and Jaenisch, R. (2000) Generation of mice from wild-type and targeted ES cells by nuclear cloning. Nat. Genet. 24 (2), 109110.

28) Byrne, J.A., Pedersen, D.A., Clepper, L.L., Nelson, M., Sanger, W.G., Gokhale, S., Wolf, D.P. and Mitalipov, S.M. (2007) Producing primate embryonic stem cells by somatic cell nuclear transfer. Nature 450 (7169), 497-502.

29) Egli, D., Chen, A.E., Saphier, G., Ichida, J., Fitzgerald, C., Go, K.J., Acevedo, N., Patel, J., Baetscher, M., Kearns, W.G., Goland, R., Leibel, R.L., Melton, D.A. and Eggan, K. (2011) Reprogramming within hours following nuclear transfer into mouse but not human zygotes. Nat. Commun. 2, 488.

30) Noggle, S., Fung, H.L., Gore, A., Martinez, H., Satriani, K.C., Prosser, R., Oum, K., Paull, D., Druckenmiller, S., Freeby, M., Greenberg, E., Zhang, K., Goland, R., Sauer, M.V., Leibel, R.L. and Egli, D. (2011) Human oocytes reprogram somatic cells to a pluripotent state. Nature $\mathbf{4 7 8}$ (7367), 70-75

31) Tachibana, M., Amato, P., Sparman, M., Gutierrez, N.M., Tippner-Hedges, R., Ma, H., Kang, E., Fulati, A., Lee, H.S., Sritanaudomchai, H. Masterson, K., Larson, J., Eaton, D., SadlerFredd, K., Battaglia, D., Lee, D., Wu, D., Jensen, J., Patton, P., Gokhale, S., Stouffer, R.L., Wolf, D. and Mitalipov, S. (2013) Human embryonic stem cells derived by somatic cell nuclear transfer. Cell 153 (6), 1228-1238.

32) Mitsui, K., Tokuzawa, Y., Itoh, H., Segawa, K., Murakami, M., Takahashi, K., Maruyama, M., Maeda, M. and Yamanaka, S. (2003) The homeoprotein Nanog is required for maintenance of pluripotency in mouse epiblast and ES cells. Cell 113 (5), 631-642.

33) Chambers, I., Colby, D., Robertson, M., Nichols, J., Lee, S., Tweedie, S. and Smith, A. (2003) Func- tional expression cloning of Nanog, a pluripotency sustaining factor in embryonic stem cells. Cell $\mathbf{1 1 3}$ (5), 643-655.

34) Takahashi, K., Mitsui, K. and Yamanaka, S. (2003) Role of ERas in promoting tumour-like properties in mouse embryonic stem cells. Nature $\mathbf{4 2 3}$ (6939), 541-545.

35) Tokuzawa, Y., Kaiho, E., Maruyama, M., Takahashi, K., Mitsui, K., Maeda, M., Niwa, H. and Yamanaka, S. (2003) Fbx15 is a novel target of Oct3/4 but is dispensable for embryonic stem cell self-renewal and mouse development. Mol. Cell. Biol. 23 (8), 2699-2708.

36) Takahashi, K. and Yamanaka, S. (2006) Induction of pluripotent stem cells from mouse embryonic and adult fibroblast cultures by defined factors. Cell 126 (4), 663-676.

37) Niwa, H., Miyazaki, J. and Smith, A.G. (2000) Quantitative expression of Oct-3/4 defines differentiation, dedifferentiation or self-renewal of ES cells. Nat. Genet. 24 (4), 372-376.

38) Okita, K., Ichisaka, T. and Yamanaka, S. (2007) Generation of germ-line competent induced pluripotent stem cells. Nature 448, 313-317.

39) Wernig, M., Meissner, A., Foreman, R., Brambrink, T., Ku, M., Hochedlinger, K., Bernstein, B.E. and Jaenisch, R. (2007) In vitro reprogramming of fibroblasts into a pluripotent ES cell-like state. Nature 448, 318-324.

40) Maherali, N., Sridharan, R., Xie, W., Utikal, J., Eminli, S., Arnold, K., Stadtfeld, M., Yachechko, R., Tchieu, J., Jaenisch, R., Plath, K. and Hochedlinger, K. (2007) Directly reprogrammed fibroblasts show global epigenetic remodelling and widespread tissue contribution. Cell Stem Cell 1 (1), 55-70.

41) Nakagawa, M., Koyanagi, M., Tanabe, K., Takahashi, K., Ichisaka, T., Aoi, T., Okita, K., Mochiduki, Y., Takizawa, N. and Yamanaka, S. (2008) Generation of induced pluripotent stem cells without Myc from mouse and human fibroblasts. Nat. Biotechnol. 26 (1), 101-106.

42) Zhao, X.Y., Li, W., Lv, Z., Liu, L., Tong, M., Hai, T., Hao, J., Guo, C.L., Ma, Q.W., Wang, L., Zeng, F. and Zhou, Q. (2009) iPS cells produce viable mice through tetraploid complementation. Nature 461 (7260), 86-90.

43) Boland, M.J., Hazen, J.L., Nazor, K.L., Rodriguez, A.R., Gifford, W., Martin, G., Kupriyanov, S. and Baldwin, K.K. (2009) Adult mice generated from induced pluripotent stem cells. Nature 461 (7260), 91-94

44) Kang, L., Wang, J., Zhang, Y., Kou, Z. and Gao, S. (2009) iPS cells can support full-term development of tetraploid blastocyst-complemented embryos. Cell Stem Cell 5 (2), 135-138.

45) Han, J., Yuan, P., Yang, H., Zhang, J., Soh, B.S., Li, P., Lim, S.L., Cao, S., Tay, J., Orlov, Y.L., Lufkin, T., Ng, H.H., Tam, W.L. and Lim, B. (2010) Tbx3 improves the germ-line competency of induced pluripotent stem cells. Nature 463 (7284), 1096-1100. 
46) Stadtfeld, M., Apostolou, E., Akutsu, H., Fukuda, A., Follett, P., Natesan, S., Kono, T., Shioda, T. and Hochedlinger, K. (2010) Aberrant silencing of imprinted genes on chromosome $12 \mathrm{qF} 1$ in mouse induced pluripotent stem cells. Nature $\mathbf{4 6 5}$ (7295), 175-181.

47) Takahashi, K., Tanabe, K., Ohnuki, M., Narita, M., Ichisaka, T., Tomoda, K. and Yamanaka, S. (2007) Induction of pluripotent stem cells from adult human fibroblasts by defined factors. Cell 131 (5), 861-872.

48) Yu, J., Vodyanik, M.A., Smuga-Otto, K., Antosiewicz-Bourget, J., Frane, J.L., Tian, S., Nie, J., Jonsdottir, G.A., Ruotti, V., Stewart, R., Slukvin, I.I. and Thomson, J.A. (2007) Induced pluripotent stem cell lines derived from human somatic cells. Science 318 (5858), 1917-1920.

49) Tanabe, K., Nakamura, M., Narita, M., Takahashi, K. and Yamanaka, S. (2013) Maturation, not initiation, is the major roadblock during reprogramming toward pluripotency from human fibroblasts. Proc. Natl. Acad. Sci. U.S.A. 110 (30), 12172-12179.

50) Hanna, J., Saha, K., Pando, B., van Zon, J., Lengner, C.J., Creyghton, M.P., van Oudenaarden, A. and Jaenisch, R. (2009) Direct cell reprogramming is a stochastic process amenable to acceleration. Nature 462 (7273), 595601.

51) Buganim, Y., Faddah, D.A., Cheng, A.W., Itskovich, E., Markoulaki, S., Ganz, K., Klemm, S.L., van Oudenaarden, A. and Jaenisch, R. (2012) Single-cell expression analyses during cellular reprogramming reveal an early stochastic and a late hierarchic phase. Cell 150 (6), 12091222 .

52) Buganim, Y., Faddah, D.A. and Jaenisch, R. (2013) Mechanisms and models of somatic cell reprogramming. Nat. Rev. Genet. 14 (6), 427-439.

53) Rais, Y., Zviran, A., Geula, S., Gafni, O., Chomsky, E., Viukov, S., Mansour, A.A., Caspi, I., Krupalnik, V., Zerbib, M., Maza, I., Mor, N., Baran, D., Weinberger, L., Jaitin, D.A., LaraAstiaso, D., Blecher-Gonen, R., Shipony, Z., Mukamel, Z., Hagai, T., Gilad, S., AmannZalcenstein, D., Tanay, A., Amit, I., Novershtern, N. and Hanna, J.H. (2013) Deterministic direct reprogramming of somatic cells to pluripotency. Nature 502 (7469), 65-70.

54) Worringer, K.A., Rand, T.A., Hayashi, Y., Sami, S., Takahashi, K., Tanabe, K., Narita, M., Srivastava, D. and Yamanaka, S. (2014) The let$7 /$ LIN-41 pathway regulates reprogramming to human induced pluripotent stem cells by controlling expression of prodifferentiation genes. Cell Stem Cell 14 (1), 40-52.

55) Polo, J.M., Anderssen, E., Walsh, R.M., Schwarz, B.A., Nefzger, C.M., Lim, S.M., Borkent, M., Apostolou, E., Alaei, S., Cloutier, J., Bar-Nur, O., Cheloufi, S., Stadtfeld, M., Figueroa, M.E., Robinton, D., Natesan, S., Melnick, A., Zhu, J., Ramaswamy, S. and Hochedlinger, K. (2012) A molecular roadmap of reprogramming somatic cells into iPS cells. Cell 151 (7), 1617-1632.

56) Soufi, A., Donahue, G. and Zaret, K.S. (2012) Facilitators and impediments of the pluripotency reprogramming factors' initial engagement with the genome. Cell 151 (5), 994-1004.

57) Kim, J., Woo, A.J., Chu, J., Snow, J.W., Fujiwara, Y., Kim, C.G., Cantor, A.B. and Orkin, S.H. (2010) A Myc network accounts for similarities between embryonic stem and cancer cell transcription programs. Cell 143 (2), 313-324.

58) Doyon, Y., Selleck, W., Lane, W.S., Tan, S. and Cote, J. (2004) Structural and functional conservation of the NuA4 histone acetyltransferase complex from yeast to humans. Mol. Cell. Biol. 24 (5), 1884-1896.

59) Fazzio, T.G., Huff, J.T. and Panning, B. (2008) Chromatin regulation $\operatorname{Tip}(60) \mathrm{s}$ the balance in embryonic stem cell self-renewal. Cell Cycle 7 (21), 3302-3306.

60) Shi, Y., Do, J.T., Desponts, C., Hahm, H.S., Scholer, H.R. and Ding, S. (2008) A combined chemical and genetic approach for the generation of induced pluripotent stem cells. Cell Stem Cell 2 (6), 525-528.

61) Huangfu, D., Osafune, K., Maehr, R., Guo, W., Eijkelenboom, A., Chen, S., Muhlestein, W. and Melton, D.A. (2008) Induction of pluripotent stem cells from primary human fibroblasts with only Oct4 and Sox2. Nat. Biotechnol. 26 (11), 12691275.

62) Mali, P., Chou, B.K., Yen, J., Ye, Z., Zou, J., Dowey, S., Brodsky, R.A., Ohm, J.E., Yu, W., Baylin, S.B., Yusa, K., Bradley, A., Meyers, D.J., Mukherjee, C., Cole, P.A. and Cheng, L. (2010) Butyrate greatly enhances derivation of human induced pluripotent stem cells by promoting epigenetic remodeling and the expression of pluripotency-associated genes. Stem Cells 28 (4), 713-720.

63) Liang, G., Taranova, O., Xia, K. and Zhang, Y. (2010) Butyrate promotes induced pluripotent stem cell generation. J. Biol. Chem. 285 (33), $25516-25521$.

64) Tahiliani, M., Koh, K.P., Shen, Y., Pastor, W.A., Bandukwala, H., Brudno, Y., Agarwal, S., Iyer, L.M., Liu, D.R., Aravind, L. and Rao, A. (2009) Conversion of 5-methylcytosine to 5-hydroxymethylcytosine in mammalian DNA by MLL partner TET1. Science 324 (5929), 930-935.

65) Kriaucionis, S. and Heintz, N. (2009) The nuclear DNA base 5-hydroxymethylcytosine is present in Purkinje neurons and the brain. Science $\mathbf{3 2 4}$ (5929), 929-930.

66) Wang, T., Wu, H., Li, Y., Szulwach, K.E., Lin, L., Li, X., Chen, I.P., Goldlust, I.S., Chamberlain, S.J., Dodd, A., Gong, H., Ananiev, G., Han, J.W., Yoon, Y.S., Rudd, M.K., Yu, M., Song, C.X., He, C., Chang, Q., Warren, S.T. and Jin, P. (2013) Subtelomeric hotspots of aberrant 5-hydroxymethylcytosine-mediated epigenetic modifications during reprogramming to pluripotency. Nat. Cell 
Biol. 15 (6), 700-711.

67) Costa, Y., Ding, J., Theunissen, T.W., Faiola, F., Hore, T.A., Shliaha, P.V., Fidalgo, M., Saunders, A., Lawrence, M., Dietmann, S., Das, S., Levasseur, D.N., Li, Z., Xu, M., Reik, W., Silva, J.C. and Wang, J. (2013) NANOG-dependent function of TET1 and TET2 in establishment of pluripotency. Nature 495 (7441), 370-374.

68) Mikkelsen, T.S., Hanna, J., Zhang, X., Ku, M., Wernig, M., Schorderet, P., Bernstein, B.E., Jaenisch, R., Lander, E.S. and Meissner, A. (2008) Dissecting direct reprogramming through integrative genomic analysis. Nature 454 (7205), 794.

69) Ichida, J.K., Blanchard, J., Lam, K., Son, E.Y., Chung, J.E., Egli, D., Loh, K.M., Carter, A.C., Di Giorgio, F.P., Koszka, K., Huangfu, D., Akutsu, H., Liu, D.R., Rubin, L.L. and Eggan, K. (2009) A small-molecule inhibitor of Tgf- $\beta$ signaling replaces Sox2 in reprogramming by inducing Nanog. Cell Stem Cell 5 (5), 491-503.

70) Thiery, J.P., Acloque, H., Huang, R.Y. and Nieto, M.A. (2009) Epithelial-mesenchymal transitions in development and disease. Cell 139 (5), 871890.

71) Li, R., Liang, J., Ni, S., Zhou, T., Qing, X., Li, H., He, W., Chen, J., Li, F., Zhuang, Q., Qin, B., Xu, J., Li, W., Yang, J., Gan, Y., Qin, D., Feng, S., Song, H., Yang, D., Zhang, B., Zeng, L., Lai, L., Esteban, M.A. and Pei, D. (2010) A mesenchymal-to-epithelial transition initiates and is required for the nuclear reprogramming of mouse fibroblasts. Cell Stem Cell 7 (1), 51-63.

72) Samavarchi-Tehrani, P., Golipour, A., David, L., Sung, H.K., Beyer, T.A., Datti, A., Woltjen, K., Nagy, A. and Wrana, J.L. (2010) Functional genomics reveals a BMP-driven mesenchymal-toepithelial transition in the initiation of somatic cell reprogramming. Cell Stem Cell 7 (1), 64-77.

73) Peinado, H., Quintanilla, M. and Cano, A. (2003) Transforming growth factor beta-1 induces snail transcription factor in epithelial cell lines: mechanisms for epithelial mesenchymal transitions. J. Biol. Chem. 278 (23), 21113-21123.

74) Peinado, H., Portillo, F. and Cano, A. (2004) Transcriptional regulation of cadherins during development and carcinogenesis. Int. J. Dev. Biol. 48 (5-6), 365-375.

75) Ying, Q.L., Nichols, J., Chambers, I. and Smith, A. (2003) BMP induction of Id proteins suppresses differentiation and sustains embryonic stem cell self-renewal in collaboration with STAT3. Cell 115 (3), 281-292.

76) Chen, J., Liu, J., Yang, J., Chen, Y., Ni, S., Song, H., Zeng, L., Ding, K. and Pei, D. (2010) BMPs functionally replace Klf4 and support efficient reprogramming of mouse fibroblasts by Oct4 alone. Cell Res. 21, 205-212.

77) Hanna, J., Wernig, M., Markoulaki, S., Sun, C.W., Meissner, A., Cassady, J.P., Beard, C., Brambrink, T., Wu, L.C., Townes, T.M. and Jaenisch, R. (2007) Treatment of sickle cell anemia mouse model with iPS cells generated from autologous skin. Science 318 (5858), 19201923.

78) Takayama, N., Nishimura, S., Nakamura, S., Shimizu, T., Ohnishi, R., Endo, H., Yamaguchi, T., Otsu, M., Nishimura, K., Nakanishi, M., Sawaguchi, A., Nagai, R., Takahashi, K., Yamanaka, S., Nakauchi, H. and Eto, K. (2010) Transient activation of $c-M Y C$ expression is critical for efficient platelet generation from human induced pluripotent stem cells. J. Exp. Med. 207, 2817-2830.

79) Kriks, S., Shim, J.W., Piao, J., Ganat, Y.M., Wakeman, D.R., Xie, Z., Carrillo-Reid, L., Auyeung, G., Antonacci, C., Buch, A., Yang, L., Beal, M.F., Surmeier, D.J., Kordower, J.H., Tabar, V. and Studer, L. (2011) Dopamine neurons derived from human ES cells efficiently engraft in animal models of Parkinson's disease. Nature 480, 547-551.

80) Nori, S., Okada, Y., Yasuda, A., Tsuji, O., Takahashi, Y., Kobayashi, Y., Fujiyoshi, K., Koike, M., Uchiyama, Y., Ikeda, E., Toyama, Y., Yamanaka, S., Nakamura, M. and Okano, H. (2011) Grafted human-induced pluripotent stemcell-derived neurospheres promote motor functional recovery after spinal cord injury in mice. Proc. Natl. Acad. Sci. U.S.A. 108 (40), 1682516830

81) Tsuji, O., Miura, K., Okada, Y., Fujiyoshi, K., Mukaino, M., Nagoshi, N., Kitamura, K., Kumagai, G., Nishino, M., Tomisato, S., Higashi, H., Nagai, T., Katoh, H., Kohda, K., Matsuzaki, Y., Yuzaki, M., Ikeda, E., Toyama, Y., Nakamura, M., Yamanaka, S. and Okano, H. (2010) Therapeutic potential of appropriately evaluated safe-induced pluripotent stem cells for spinal cord injury. Proc. Natl. Acad. Sci. U.S.A. 107 (28), 12704-12709.

82) Araki, R., Uda, M., Hoki, Y., Sunayama, M., Nakamura, M., Ando, S., Sugiura, M., Ideno, H., Shimada, A., Nifuji, A. and Abe, M. (2013) Negligible immunogenicity of terminally differentiated cells derived from induced pluripotent or embryonic stem cells. Nature 494 (7435), 100104.

83) Guha, P., Morgan, J.W., Mostoslavsky, G., Rodrigues, N.P. and Boyd, A.S. (2013) Lack of immune response to differentiated cells derived from syngeneic induced pluripotent stem cells. Cell Stem Cell 12 (4), 407-412.

84) Morizane, A., Doi, D., Kikuchi, T., Okita, K., Hotta, A., Kawasaki, T., Hayashi, T., Onoe, H., Shiina, T., Yamanaka, S. and Takahashi, J. (2013) Direct comparison of autologous and allogeneic transplantation of iPSC-derived neural cells in the brain of a non-human primate. Stem Cell Reports 1, 283-292.

85) Stacey, G.N., Crook, J.M., Hei, D. and Ludwig, T. (2013) Banking human induced pluripotent stem cells: lessons learned from embryonic stem cells? Cell Stem Cell 13 (4), 385-388. 
86) Turner, M., Leslie, S., Martin, N.G., Peschanski, M., Rao, M., Taylor, C.J., Trounson, A., Turner, D., Yamanaka, S. and Wilmut, I. (2013) Toward the development of a global induced pluripotent stem cell library. Cell Stem Cell 13 (4), 382-384.

87) Okita, K., Yamakawa, T., Matsumura, Y., Sato, Y., Amano, N., Watanabe, A., Goshima, N. and Yamanaka, S. (2013) An efficient nonviral method to generate integration-free human-induced pluripotent stem cells from cord blood and peripheral blood cells. Stem Cells 31 (3), 458-466.

88) Okita, K., Hong, H., Takahashi, K. and Yamanaka, S. (2010) Generation of mouse-induced pluripotent stem cells with plasmid vectors. Nat. Protoc. 5 (3), 418-428.

89) Okita, K., Matsumura, Y., Sato, Y., Okada, A., Morizane, A., Okamoto, S., Hong, H., Nakagawa, M., Tanabe, K., Tezuka, K., Shibata, T., Kunisada, T., Takahashi, M., Takahashi, J., Saji, H. and Yamanaka, S. (2011) A more efficient method to generate integration-free human iPS cells. Nat. Methods 8 (5), 409-412.

90) Fusaki, N., Ban, H., Nishiyama, A., Saeki, K. and Hasegawa, M. (2009) Efficient induction of transgene-free human pluripotent stem cells using a vector based on Sendai virus, an RNA virus that does not integrate into the host genome. Proc. Jpn. Acad., Ser. B, Phys. Biol. Sci. 85 (8), 348362.

91) Seki, T., Yuasa, S., Oda, M., Egashira, T., Yae, K., Kusumoto, D., Nakata, H., Tohyama, S., Hashimoto, H., Kodaira, M., Okada, Y., Seimiya, H., Fusaki, N., Hasegawa, M. and Fukuda, K. (2010) Generation of induced pluripotent stem cells from human terminally differentiated circulating T cells. Cell Stem Cell 7 (1), $11-14$.

92) Nishimura, K., Sano, M., Ohtaka, M., Furuta, B., Umemura, Y., Nakajima, Y., Ikehara, Y., Kobayashi, T., Segawa, H., Takayasu, S., Sato, H., Motomura, K., Uchida, E., Kanayasu-Toyoda, T., Asashima, M., Nakauchi, H., Yamaguchi, T. and Nakanishi, M. (2010) Development of defective and persistent Sendai virus vector: a unique gene delivery/expression system ideal for cell reprogramming. J. Biol. Chem. 286, 4760-4771.

93) Eiraku, M., Watanabe, K., Matsuo-Takasaki, M., Kawada, M., Yonemura, S., Matsumura, M., Wataya, T., Nishiyama, A., Muguruma, K. and Sasai, Y. (2008) Self-organized formation of polarized cortical tissues from ESCs and its active manipulation by extrinsic signals. Cell Stem Cell $\mathbf{3}$ (5), 519-532.

94) Eiraku, M., Takata, N., Ishibashi, H., Kawada, M., Sakakura, E., Okuda, S., Sekiguchi, K., Adachi, T. and Sasai, Y. (2011) Self-organizing opticcup morphogenesis in three-dimensional culture. Nature 472 (7341), 51-56.

95) Suga, H., Kadoshima, T., Minaguchi, M., Ohgushi, M., Soen, M., Nakano, T., Takata, N., Wataya, T., Muguruma, K., Miyoshi, H., Yonemura, S., Oiso, Y. and Sasai, Y. (2011) Self-formation of functional adenohypophysis in three-dimensional culture. Nature 480 (7375), 57-62.

96) Kobayashi, T., Yamaguchi, T., Hamanaka, S., Kato-Itoh, M., Yamazaki, Y., Ibata, M., Sato, H., Lee, Y.S., Usui, J., Knisely, A.S., Hirabayashi, M. and Nakauchi, H. (2010) Generation of rat pancreas in mouse by interspecific blastocyst injection of pluripotent stem cells. Cell 142 (5), $787-799$

97) Takebe, T., Sekine, K., Enomura, M., Koike, H., Kimura, M., Ogaeri, T., Zhang, R.R., Ueno, Y., Zheng, Y.W., Koike, N., Aoyama, S., Adachi, Y. and Taniguchi, H. (2013) Vascularized and functional human liver from an iPSC-derived organ bud transplant. Nature 499 (7459), 481-484.

98) Dimos, J.T., Rodolfa, K.T., Niakan, K.K., Weisenthal, L.M., Mitsumoto, H., Chung, W., Croft, G.F., Saphier, G., Leibel, R., Goland, R., Wichterle, H., Henderson, C.E. and Eggan, K. (2008) Induced pluripotent stem cells generated from patients with ALS can be differentiated into motor neurons. Science 321, 1218-1221.

99) Ebert, A.D., Yu, J., Rose, F.F. Jr., Mattis, V.B., Lorson, C.L., Thomson, J.A. and Svendsen, C.N. (2009) Induced pluripotent stem cells from a spinal muscular atrophy patient. Nature $\mathbf{4 5 7}$ (7227), 277-280.

100) Lee, T.H., Song, S.H., Kim, K.L., Yi, J.Y., Shin, G.H., Kim, J.Y., Kim, J., Han, Y.M., Lee, S.H., Shim, S.H. and Suh, W. (2009) Functional recapitulation of smooth muscle cells via induced pluripotent stem cells from human aortic smooth muscle cells. Circ. Res. 106 (1), 120-128.

101) Egawa, N., Kitaoka, S., Tsukita, K., Naitoh, M., Takahashi, K., Yamamoto, T., Adachi, F., Kondo, T., Okita, K., Asaka, I., Aoi, T., Watanabe, A., Yamada, Y., Morizane, A., Takahashi, J., Ayaki, T., Ito, H., Yoshikawa, K., Yamawaki, S., Suzuki, S., Watanabe, D., Hioki, H., Kaneko, T., Makioka, K., Okamoto, K., Takuma, H., Tamaoka, A., Hasegawa, K., Nonaka, T., Hasegawa, M., Kawata, A., Yoshida, M., Nakahata, T., Takahashi, R., Marchetto, M.C., Gage, F.H., Yamanaka, S. and Inoue, H. (2012) Drug screening for ALS using patient-specific induced pluripotent stem cells. Sci. Transl. Med. 4 (145), $145 \mathrm{ra} 104$.

102) Kim, Y.G., Cha, J. and Chandrasegaran, S. (1996) Hybrid restriction enzymes: zinc finger fusions to Fok I cleavage domain. Proc. Natl. Acad. Sci. U.S.A. 93 (3), 1156-1160.

103) Hockemeyer, D., Soldner, F., Cook, E.G., Gao, Q., Mitalipova, M. and Jaenisch, R. (2008) A druginducible system for direct reprogramming of human somatic cells to pluripotency. Cell Stem Cell 3 (3), 346-353.

104) Mashimo, T., Takizawa, A., Kobayashi, J., Kunihiro, Y., Yoshimi, K., Ishida, S., Tanabe, K., Yanagi, A., Tachibana, A., Hirose, J., Yomoda, J., Morimoto, S., Kuramoto, T., Voigt, B., Watanabe, T., Hiai, H., Tateno, C., Komatsu, K. and Serikawa, T. (2012) Generation and 
characterization of severe combined immunodeficiency rats. Cell Rep. 2 (3), 685-694.

105) Boch, J. and Bonas, U. (2010) Xanthomonas AvrBs3 family-type III effectors: discovery and function. Annu. Rev. Phytopathol. 48, 419-436.

106) Hockemeyer, D., Wang, H., Kiani, S., Lai, C.S. Gao, Q., Cassady, J.P., Cost, G.J., Zhang, L., Santiago, Y., Miller, J.C., Zeitler, B., Cherone, J.M., Meng, X., Hinkley, S.J., Rebar, E.J., Gregory, P.D., Urnov, F.D. and Jaenisch, R. (2011) Genetic engineering of human pluripotent cells using TALE nucleases. Nat. Biotechnol. 29 (8), 731-734

107) Jinek, M., Chylinski, K., Fonfara, I., Hauer, M., Doudna, J.A. and Charpentier, E. (2012) A programmable dual-RNA-guided DNA endonuclease in adaptive bacterial immunity. Science 337 (6096), 816-821.

(Received Oct. 30, 2013; accepted Jan. 8, 2014)

\section{Profile}

Professor Shinya Yamanaka received his M.D. from Kobe University in 1987 and a Ph.D. from Osaka City University Graduate School in 1993. After working as a postdoctoral fellow at the Gladstone Institute of Cardiovascular Disease in San Francisco, he became an assistant professor at Osaka City University in 1996. He was appointed as an associate professor at the Nara Institute of Science and Technology in 1999, and a professor in 2003. He moved to Kyoto University in 2004, and since 2008, Yamanaka serves as the director of the Center for iPS Cell Research and Application (CiRA) at Kyoto University. He has received awards including "Albert Lasker Basic Medical Research Award" in 2009, "Imperial Prize and Japan Academy Prize" in 2010, "Kyoto Prize" in 2010, and "Wolf Prize" in 2011, and "Nobel Prize in Physiology or

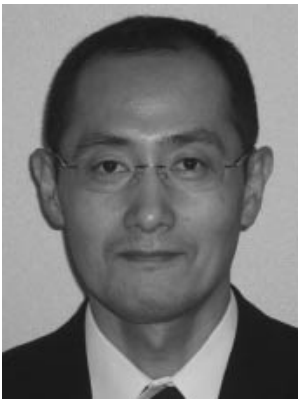

Medicine" in 2012. He was elected a member of the Japan Academy in 2013. He also-serves as a senior investigator at Gladstone, a foreign associate of the U.S. National Academy of Sciences and a member of the Pontifical Academy of Sciences. 